\title{
ANALYZING THE IMPACT OF TEMPERATURE ON AXOPLASMIC FLUID PROPERTIES DEFINING NEURONAL EXCITATION
}

\author{
S. Bhatia ${ }^{1, *}$, P. Sharma ${ }^{2}$, P. Singh ${ }^{3}$, P. Bhatia ${ }^{4}$
}

\begin{abstract}
Axoplasmic fluid properties for neuronal excitation have been investigated with respect to temperature. Density, the mass fraction of ions and rate of addition of ions are the parameters considered for characterizing axoplasmic fluid properties. The behavior of these parameters has been analyzed with respect to the changes in temperature ranging from -5 degree Celsius to 35 degree Celsius. The temperature has been defined using $\mathrm{Q}_{10 \mathrm{of}} 3$ coefficient as done in the Hodgkin-Huxley model. The trend of these parameters at different temperatures has been depicted along the axonal length represented through $\mathrm{x}$-axis of the graphs. The conduction velocities of the above said parameters have also been recorded at different temperatures. The range $[-5,35]$ degree Celsius has been increased by 20 degrees, 10 degree on the lower side and 10 degree on the upper side of the range $[-5,25]$ degree Celsius and it is found that temperature dependency using $\mathrm{Q}_{100 \mathrm{f} 3}$ coefficient for said parameters is valid only in the temperature ranging from 5 degree Celsius to 25 degree Celsius as it is for membrane voltage in the Hodgkin-Huxley model. These findings strongly support the obtained results and also suggest obtaining the temperature coefficient value which is applicable for a wider range of temperatures impacting neuronal excitation.
\end{abstract}

\section{Keywords: Axoplasmic fluid properties, Temperature Dependency, Neuronal Excitation}

\section{INTRODUCTION}

Information transmission is one of the important features that differentiate neurons from other cells. Different types of neurons perform different types of functions both in animals and in the human body. Sensory neurons are responsible for transmitting the signal received from the sensory cells present in the body to the brain, whereas motor neurons direct the movement of body muscles based on the signal received from the brain. There are interneurons also which play a vital role in the transmission of signal among the other different neurons of the body.

Depending upon the types of neuron, the neuron structure [1] may vary from one neuron to another. Three main components defining the basic structure of a neuron are dendrites, soma (the cell body) and the axon. Dendrites, also known as "receiving entities" receive inputs from other neurons at the synapse and transmit them to the soma, if the received signal is excitatory. Soma comprises of a nucleus and other organelles for performing the intended cellular functions. The axon carries the output received from soma to the other cells through synaptic connections. Synaptic connections are represented by the axonal end of a neuron connected to dendritic branches. These dendritic branches may vary in a number ranging from thousands to lakhs for receiving the signals. Axon is considered to be an important component of a neuron, since it receives the information in the form of action potential from the soma, and transmits it to the axonal end, from where the signal is further transmitted to another neuron.

The nucleus of the soma is surrounded by the cytoplasm which further contains the cytosol and the other organelles that define the neuron's internal structure. Cytoplasm is present throughout the cell membrane and cytosol is contained only within the cytoplasm. Cytoplasm present in the axon of the neuronal cell is termed as axoplasm. Axoplasm comprises 87 percent of water and hence axoplasm has been treated as fluid in [2].

The important phenomenon through which the neuronal functioning is identified is the action potential [3]. Action potential is also termed as nerve impulse, spike and neuronal excitation. A neuron is said to be excitable whenever it generates action potential. An action potential is generated as soon as the membrane

This paper was recommended for publication in revised form by Regional Editor Balaram Kundu

${ }^{1}$ Department of Computer Science Engineering, Faculty of Engineering and Technology, Manav Rachna International Institute of Research and Studies, Faridabad(121004). Orcid id: 0000-0001-7525-0299

${ }^{2}$ Department of Applied Sciences, The NorthCap University, Gurugram (122017). Orcid id: 0000-0003-2338-306X

${ }^{3}$ Department of Mathematics, Central University of Haryana, Mahendragarh, Haryana (123031). Orcid id: 0000-0003-4878-8581

${ }^{4}$ Department of Mechanical Engineering, The NorthCap Universit, Gurugram, Haryana(122017). Orcid id: 0000-0002-0111-4806

*E-mail address: ersuman80@gmail.com

Manuscript Received 13 April 2018, Accepted 16 October 2018 
voltage crosses its threshold when ion channels that span across the membrane are opened and allow the ions to move across the membrane. Generated action potential further propagates down the axon length and is known as action potential propagation.

Temperature is one of the most important factors impacting information transfer in the form of spike generation followed by spike propagation. It has been stated that an increase in temperature results in exponentially increased energy efficiency and hence increased the rate of sodium ions inactivation leading to reduced spike duration [4]. The importance of temperature as a physical parameter has also been reflected in the Hodgkin-Huxley model (H-H model), since the temperature coefficient $\mathrm{Q}_{10 \mathrm{of} 3}$ has been incorporated [5].

Research performed for investigation of the effect of temperature on action potential has shown that with a stimulus applied for $1 \mathrm{msec}$ duration, threshold decreases with increase in temperature whereas for stimulus application of $100 \mathrm{msec}$ duration, the threshold increases with increase in temperature [6]. These facts were further analyzed in [7], where it has been observed that at lower temperatures, the threshold is decreased and at higher temperatures, the threshold required for spike generation is increased. Research performed by Chapman [8] has analyzed action potential conduction velocity with respect to temperature, where it has been observed that conduction velocity follows temperature dependency as defined through $\mathrm{Q}_{100 \mathrm{o} 3}$ coefficient by Hodgkin and Huxley within the range of 5 degree Celsius to 25 degree Celsius. Thermal comfort degree [9] has also been computed for human beings by utilizing the $\mathrm{H}-\mathrm{H}$ model and its impact on neuronal excitation, air temperature, velocity, biological activity and metabolic rate. For cardiac attack, international guidelines suggest therapeutic hypothermia in [10]. The authors have provided the results based on clinical investigations performed on 950 patients. As per their clinical investigations, temperature of 36 degree Celsius has been suggested to be maintained for unconscious patients that can be caught in case of out-of-hospital cardiac attack for their survival and also avoiding neurological disorders. Research has also been performed to investigate the effects of hypothermia induced seizures on SCN1-A mutation [11]. The adverse effects of hyperthermia have been explained in [12]. In this work, the authors have explained how hyperthermia can result in neurological dysfunction as well as cognitive dysfunction. They have also explained the mechanism of cerebral damage in presence of hyperthermia, which first starts the damage at the cellular level.

Impact of temperature has been studied on membrane voltage [8] and ionic conductance [13] using the $\mathrm{H}-\mathrm{H}$ model. The model proposed in [2] for neuronal excitation based on axoplasmic fluid properties has investigated the impact of temperature on action potential propagation velocity and axoplasmic fluid viscosity. Their model incorporates other parameters namely: density, the mass fraction of ions, the rate of addition of ions and temperature dependent longitudinal diffusivity. Temperature dependency has been investigated for action potential and viscosity [14].

Considering the fact that temperature is a very crucial parameter for neuronal excitation, it becomes important to analyze the above-said parameters with respect to changes in temperature, since the mass fraction and the rate of addition of ions impact ionic diffusion. To fill this research gap, in this paper, we have tried to analyze the impact of temperature on density, mass fraction of ions and the rate of addition of all ions. The analysis has been performed for temperature ranging from -5 degree Celsius to 35 degree Celsius. There is an increase of 10 degree on the lower end as well as on the upper end for the temperature range considered in the $\mathrm{H}$ H model.

For performing the analysis, the model describing neuronal excitation using axoplasmic fluid properties has been utilized. Results describing the impact of variation in temperature on above-said parameters have also been further analyzed for understanding how they impact the action potential.

\section{DESCRIPTION OF THE MODEL}

Bhatia et al. [2], have extended the $\mathrm{H}-\mathrm{H}$ model to define neuronal excitation in terms of axoplasmic fluid parameters. The parameters taken in the model are density, mass fraction of ions, rate of addition of ions, longitudinal diffusivity and axoplasmic fluid viscosity along with temperature which has already been considered in the $\mathrm{H}-\mathrm{H}$ model [5]. The equation for membrane voltage is written as given below:

$$
\frac{\partial\left(\rho Y_{N a}\right)}{M_{N a} \partial t} z_{N a}+\frac{\partial\left(\rho Y_{k}\right)}{M_{k} \partial t} z_{K}+\frac{\partial\left(\rho Y_{L}\right)}{M_{L} \partial t} z_{L}=\frac{2}{r F} \times c_{m} \frac{d V}{d t}-i_{a p p}
$$


Equation (1) represents the charge accumulated across the capacitor per unit time in terms of total charge increased due to sodium, potassium and chlorine ions per unit time represented through first, second and third terms respectively on the L.H.S of the above equation.

Since stimulus is applied only for once, $i_{\text {app }}$ can be considered to be zero. Hence equation (1) can be written as follows:

$$
\frac{\partial\left(\rho Y_{N a}\right)}{M_{N a} \partial t} z_{N a}+\frac{\partial\left(\rho Y_{k}\right)}{M_{k} \partial t} z_{K}+\frac{\partial\left(\rho Y_{L}\right)}{M_{L} \partial t} z_{L}=\frac{2}{r F} \times c_{m} \frac{d V}{d t}
$$

Here $Y_{N a}, Y_{K}$ and $Y_{L}$ represent the mass fraction of sodium, potassium and chlorine ions respectively and given through the following equations:

$$
\begin{aligned}
& \frac{\partial\left(\rho Y_{N a}\right)}{\partial t}=\frac{\partial}{\partial x}\left(\rho D_{N a} \frac{\partial Y_{N a}}{\partial x}\right)+\dot{\omega}_{N a}^{\prime \prime \prime}+\frac{\partial}{\partial x}\left(\frac{\rho D_{N a} z_{N a} F Y_{N a}}{R_{u} T} \frac{\partial V}{\partial x}\right) \\
& \frac{\partial\left(\rho Y_{K}\right)}{\partial t}=\frac{\partial}{\partial x}\left(\rho D_{K} \frac{\partial Y_{K}}{\partial x}\right)+\dot{\omega}_{K}^{\prime \prime \prime}+\frac{\partial}{\partial x}\left(\frac{\rho D_{K} z_{K} F Y_{K}}{R_{u} T} \frac{\partial V}{\partial x}\right) \\
& \frac{\partial\left(\rho Y_{L}\right)}{\partial t}=\frac{\partial}{\partial x}\left(\rho D_{L} \frac{\partial Y_{L}}{\partial x}\right)+\dot{\omega}_{L}^{\prime \prime \prime}+\frac{\partial}{\partial x}\left(\frac{\rho D_{L} z_{L} F Y_{L}}{R_{u} T} \frac{\partial V}{\partial x}\right)
\end{aligned}
$$

Left hand side of equations: (3), (4) and (5) represent the total increase in sodium, potassium and chlorine ions per unit time. This increase has been reflected in terms of three factors represented on the right hand side of respective equations. One of the factors is ionic diffusion due to concentration difference, second is ionic transport because of opening and closing of ionic channels and third factor is transport of ions resulted from the charge density.

Ionic transport that takes place due to opening and closing of ionic channels is represented through the following equations: (6), (7) and(8) respectively for sodium, potassium and chlorine ions and written as follows:

$$
\begin{aligned}
& \dot{\omega}_{N a}^{\prime \prime \prime}=-\frac{M_{N a}}{z_{N a} F} \frac{2}{r} \bar{g}_{N a} m^{3} h\left(V-V_{N a}\right) \\
& \dot{\omega}_{K}^{\prime \prime \prime}=-\frac{M_{K}}{z_{K} F} \frac{2}{r} \bar{g}_{K} n^{4}\left(V-V_{K}\right) \\
& \dot{\omega}_{L}^{\prime \prime \prime}=\frac{M_{L}}{z_{L} F} \frac{2}{r} \bar{g}_{L}\left(V-V_{L}\right)
\end{aligned}
$$

The value of dimensionless gating variables $\mathrm{n}, \mathrm{m}$ and $h$ lies within 0 and 1 and the rate at which these variables change with time is represented by following three equations:

$$
\frac{d n}{d t}=\alpha_{n}(1-n)-\beta_{n} n
$$




$$
\begin{aligned}
& \frac{d m}{d t}=\alpha_{m}(1-m)-\beta_{m} m \\
& \frac{d h}{d t}=\alpha_{h}(1-h)-\beta_{h} h
\end{aligned}
$$

Opening and closing of ionic channels [15] is defined through $\alpha$ 's and $\beta$ 's, which are further dependent upon the instantaneous membrane voltage as given below in equations: (12) to (14). Opening and closing of potassium ions associated with activation variable $n$ is represented through $\alpha_{n}$ and $\beta_{n}, \alpha_{m}$ and $\beta_{m}$ represent opening and closing associated with activation variable $m$, whereas $\alpha_{h}$ and $\beta_{h}$ representing opening and closing of sodium ion channels is associated with inactivation variable $h$.

$$
\begin{aligned}
& \alpha_{n}(V)=0.01 \frac{75-V}{\exp ((75-V) / 10)-1} \\
& \beta_{n}(V)=0.125 \exp (-(V+65) / 80) \\
& \alpha_{m}(V)=0.1 \frac{90-V}{\exp ((90-V) / 10)-1} \\
& \beta_{m}(V)=4 \exp (-(V+65) / 18) \\
& \alpha_{h}(V)=0.07 \exp (-(V+65) / 20) \\
& \beta_{h}(V)=\frac{1}{\exp ((95-V) / 10)+1}
\end{aligned}
$$

All the above equations representing the opening and closing rate of ion channels are multiplied by the temperature coefficient $\mathrm{Q}_{10 \mathrm{of3}}$. The value of $\mathrm{Q}_{10 \mathrm{of} 3}$ is: $3($ Temp -6.3$\left.) /(10)\right)$. Here, Temp represents temperature variable in degree Celsius.

The total rate at which the ions are added per unit volume per unit time is given by $S_{c}$

$$
S_{c}=\dot{\omega}_{N a}^{\prime \prime \prime}+\dot{\omega}_{K}^{\prime \prime \prime}+\dot{\omega}_{L}^{\prime \prime \prime}
$$

The source term can also be written in terms of mass added per unit volume per unit time as given below:

$$
\frac{\partial \rho}{\partial t}=S_{c}
$$

Longitudinal diffusivities of ions in equations: (3), (4) and (5) are represented as follows:

$$
D_{i}=\frac{k_{B} T}{6 \pi v i s_{F} \operatorname{rad}_{i}}
$$

The subscript $i$ represents $\mathrm{Na}^{+}, \mathrm{K}^{+}$and $\mathrm{Cl}^{-}$for sodium, potassium and chlorine ions respectively and the axoplasmic fluid viscosity $\left(v i S_{F}\right)$ is computed by the formula given below: 


$$
v i s_{F}=K v i s_{w}
$$

In the above formula, $\mathrm{K}$ is a constant and $v i S_{w}$ is the viscosity of water.

Expression for viscosity of water is given as follows:

$$
v i S_{w}=2.414 \times 10^{-5} \times 10^{\frac{247.8}{T-140}}
$$

Faraday constant, universal gas constant and ionic valency are also part of the model.

\section{IMPLEMENTATION}

The computational code has been written in C++ to implement the model and the model has been further investigated for analyzing the impact of temperature on density, mass fraction of ions and rate of addition of ions. For implementing the model, the length of axon (axonal length) has been taken to $1 \mathrm{~m}$ and radius of axon has been taken to $0.000238 \mathrm{~m}$. The axonal length has been further divided into 10,000 nodes and stimulus of $0.3325 \mathrm{~A} / \mathrm{m}^{2}$ has been applied at the very first node.

Since the model has been solved for one-dimension, the governing equations of the model have been solved using finite differencing method and the center differencing method. The discretized equations have then been solved computationally in an iterative manner at all the locations for each time step. The value of time step $d t$ has been taken to be $0.01 \mathrm{msec}$. For handling unstable and non-linear behavior of the equations describing the model, an under-relaxation factor of 0.05 has been used.

The values of different parameters for solving the model are given below [16].

Table 1. Values of different parameters for analyzing the impact of temperature on axoplasmic fluid properties

\begin{tabular}{|l|c|}
\hline Parameters & Values [dimensions] \\
\hline $\bar{g}_{N a}$ & $1200\left[\mathrm{~S} / \mathrm{m}^{2}\right]$ \\
\hline $\bar{g}_{K}$ & $3600\left[\mathrm{~S} / \mathrm{m}^{2}\right]$ \\
\hline $\bar{g}_{L}$ & $3\left[\mathrm{~S} / \mathrm{m}^{2}\right]$ \\
\hline $\mathrm{V}_{\mathrm{Na}}$ & $0.050[\mathrm{~V}]$ \\
\hline $\mathrm{V}_{\mathrm{K}}$ & $-0.077[\mathrm{~V}]$ \\
\hline $\mathrm{V}_{\mathrm{L}}$ & $-0.054[\mathrm{~V}]$ \\
\hline $\mathrm{c}_{\mathrm{m}}$ & $0.01\left[\mathrm{~F} / \mathrm{m}^{2}\right]$ \\
\hline
\end{tabular}

\section{RESULTS AND DISCUSSION}

The graphs demonstrate how the temperature impacts the parameters namely: density, mass fraction of ions and total rate of addition of ions represented through Sc. Analysis has been performed with temperature ranging from -5 degree Celsius to 35 degree Celsius and all the graphs have been plotted at time $t=7 \mathrm{msec}$ for the above said temperature range. We have also taken into consideration the negative range to analyze how action potential propagation velocity reduced at a negative temperature and hence to check whether this effect can be utilized for anesthesia for inhibiting the action potential propagation.

Above said temperature range has been further divided into three ranges of temperatures: First range is from -5 degree Celsius to -0.9 degree Celsius. The second range for all the parameters begins from 5 degree Celsius. End of the interval of each parameter is determined by the temperature at which the rate of conduction velocity changes. The third range for each parameter begins from the end of the second range till 35 degree Celsius. The results obtained in the temperature range between -0.8 degree Celsius to 4.9 degree Celsius have not been demonstrated, since, there is not any major variation in the action potential propagation velocity in the said range. 


\section{Analyzing the Impact of Negative Temperature on Different Parameters}

1. As can be observed from the graphical representations, that for each and every parameter when subjected to negative temperature, complete waves for the corresponding parameters are not visible. This is because of very small increase in conduction velocity of all parameters.

2. The membrane voltage crosses its threshold and action potential is generated, but the rate at which the action potential travels is very slow.

3. If observed carefully, the width of waves for all the parameters is same at all the temperatures taken in the negative range.

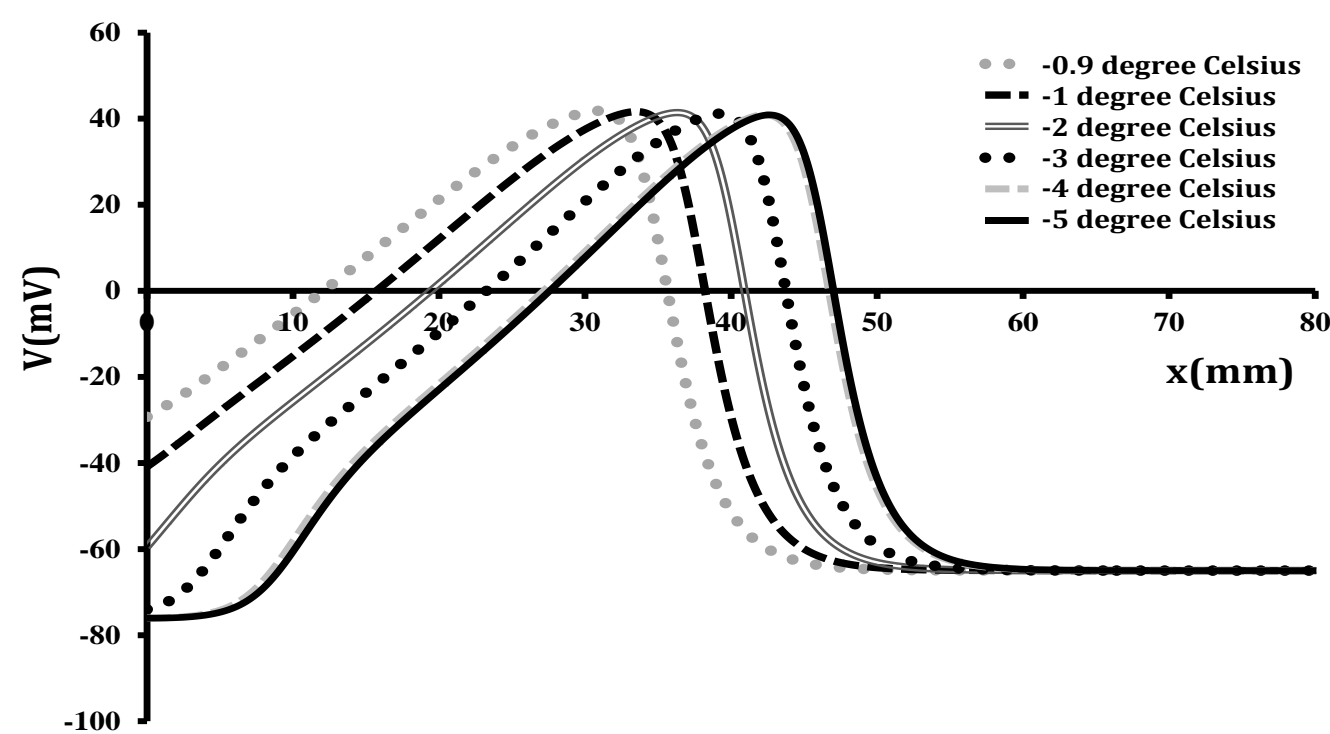

Figure 1(a)

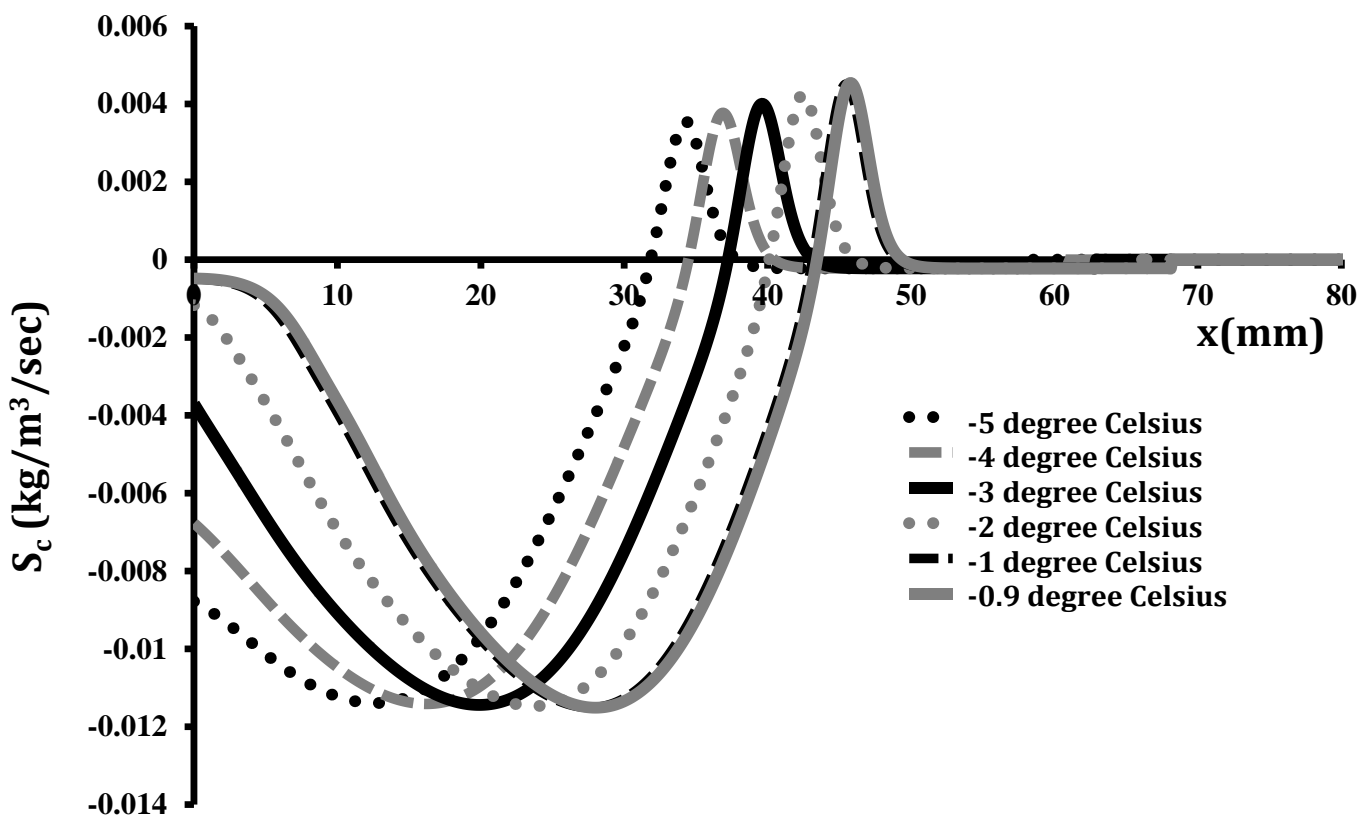

Figure 1(b) 


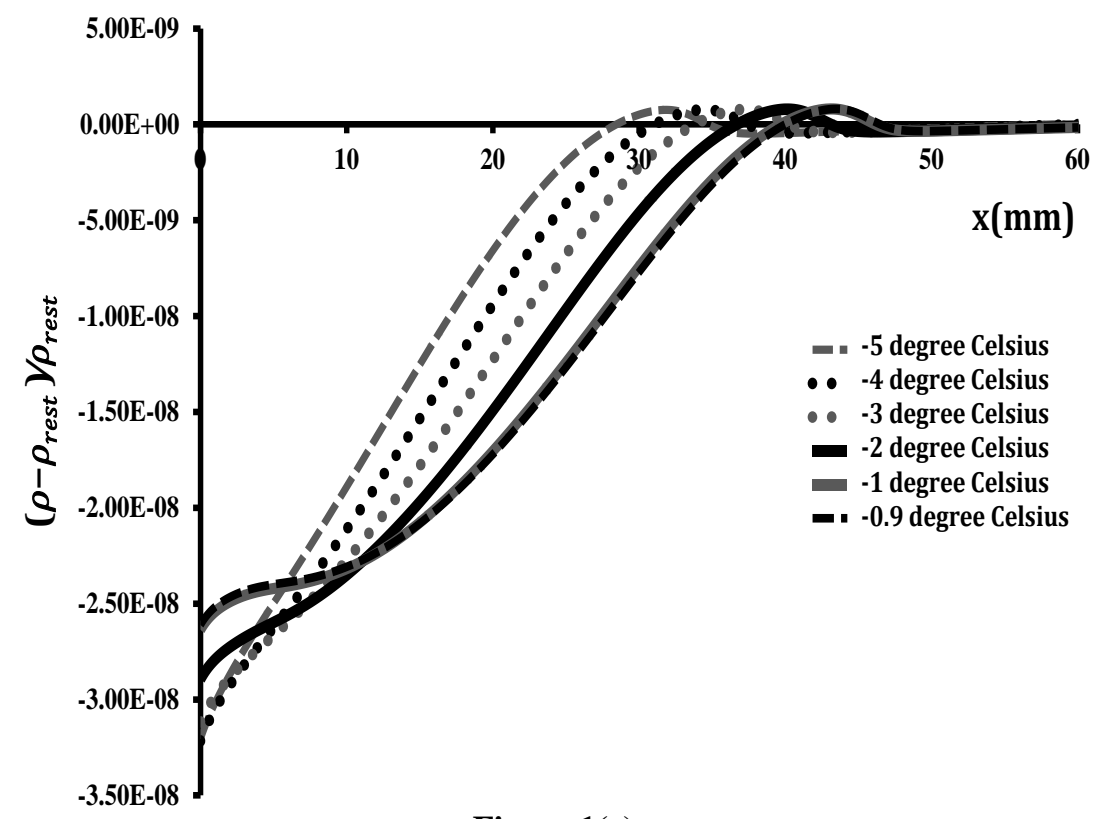

Figure 1(c)



Figure 1(d)

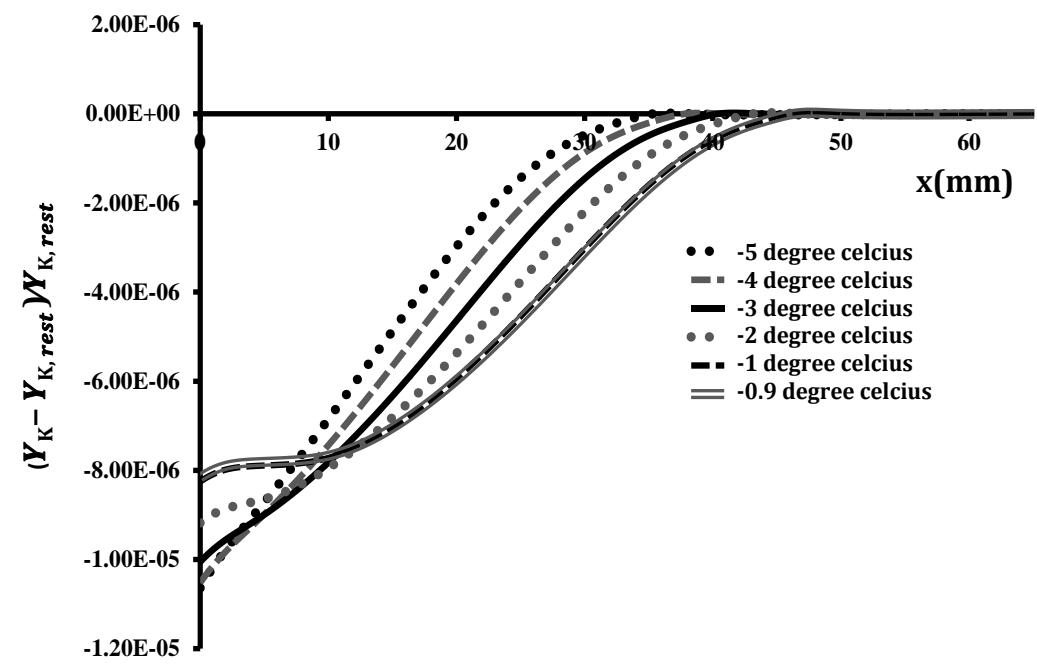

Figure 1(e) 


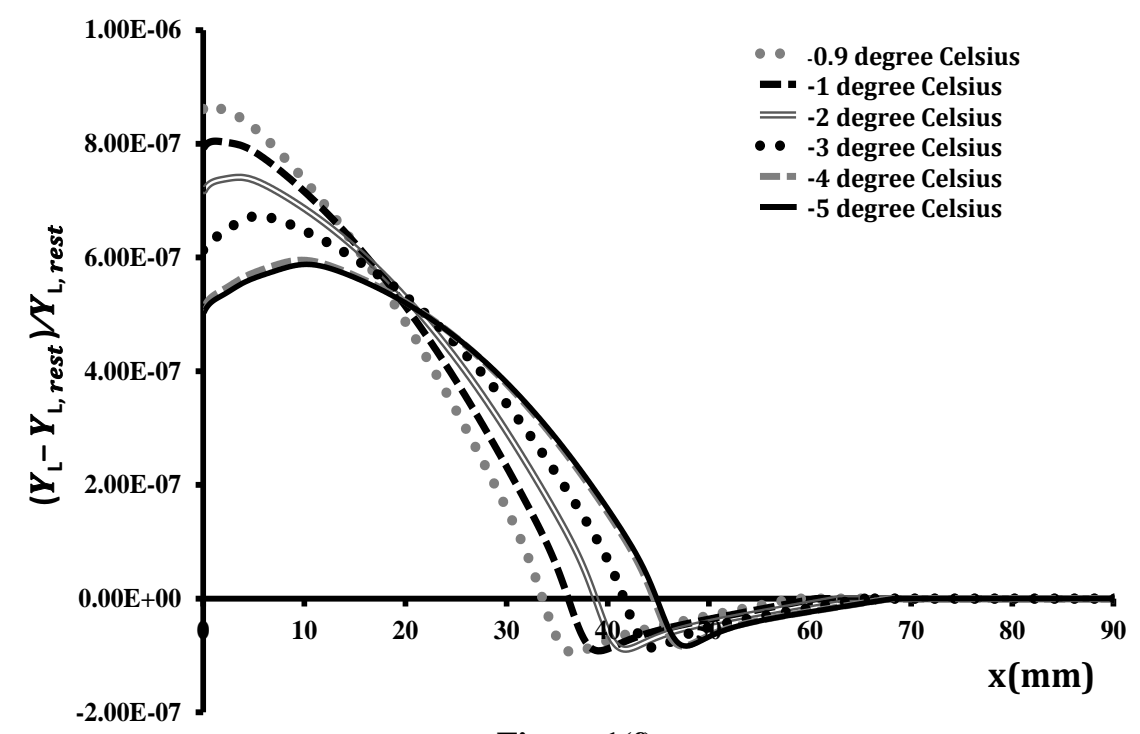

Figure 1(f)

Figure 1. Dependency of (a) membrane voltage, $V(\mathrm{mV})$ (y-axis), (b) normalized density, $\left(\rho-\rho_{\text {rest }}\right) / \rho_{\text {rest }}(y$-axis) (c) total rate of addition of all the three ions, $\mathrm{S}_{\mathrm{c}}(\mathrm{kg} / \mathrm{m} 3 / \mathrm{sec}$ ) (y-axis), (d) normalized mass fraction of sodium ions $\left(\mathrm{Y}_{\mathrm{Na}}-\mathrm{Y}_{\mathrm{Na} \text {,rest }}\right) / \mathrm{Y}_{\mathrm{Na} \text {,rest }}\left(\mathrm{y}\right.$-axis), (e) normalized mass fraction of potassium ions $\left(\mathrm{Y}_{\mathrm{K}}-\mathrm{Y}_{\mathrm{K}, \text { rest }}\right) / \mathrm{Y}_{\mathrm{K} \text {,rest }}(\mathrm{y}$-axis) and (f) normalized mass fraction of chlorine ions $\left(\mathrm{Y}_{\mathrm{L}}-\mathrm{Y}_{\mathrm{L}, \text { rest }}\right) / \mathrm{Y}_{\mathrm{L} \text {,rest }}(\mathrm{y}$-axis$)$ on temperature ranging from -5 degree

Celsius to -0.9 degree Celsius has been plotted over the axonal length $\mathrm{x}(\mathrm{mm})$ (x-axis)

Analyzing the Impact of Temperature Ranging from 5 Degree Celsius to the Temperature at Which There Is Variation In The Rate At Which The Conduction Velocity/Propagation Velocity Of Different Parameter Changes

1. The peak of all the parameters decreases with increase in temperature from 5 degree onwards.

2. Also there is a decrease in width of the waves of all the parameters with an increase in temperature.

But, the temperature at which the deviation takes place in the rate of conduction velocity/propagation velocity is different for different parameters and is given below:

i. The peak of membrane voltage falls to negative peak at a temperature of 30 degree Celsius [Figure 2(a)].

ii. The change in trend of density can be observed at a temperature of 25 degree Celsius [Figure 2(b)]

iii. The rate at which ions are added to the membrane per unit volume per unit time increases with increase in temperature ranging from 5 degree Celsius to 25 degree Celsius, hence it is the rate of addition due to all the three ions namely, sodium, potassium and chlorine that impacts the action potential generation and its further propagation [Figure 2(c)].

iv. The mass fraction of sodium, potassium and chlorine ions are almost overlapping at temperature of 30 degree and 31 degree Celsius [Figures: 2(d), 2(e) and 2(f)]. 


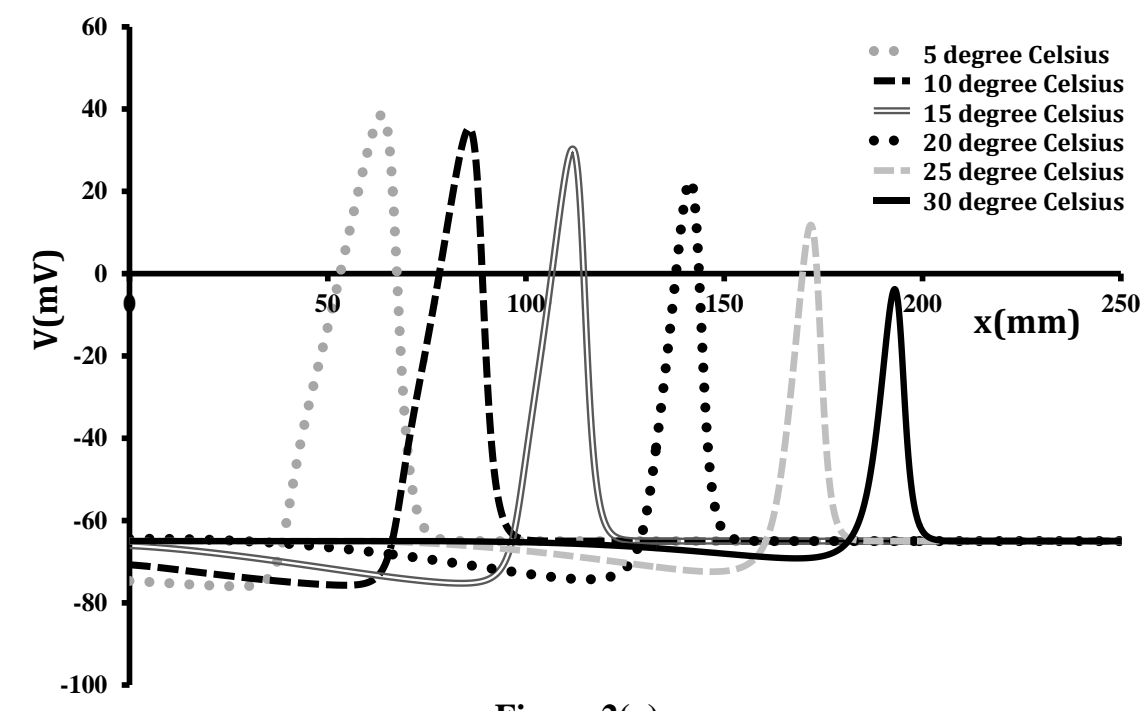

Figure 2(a)

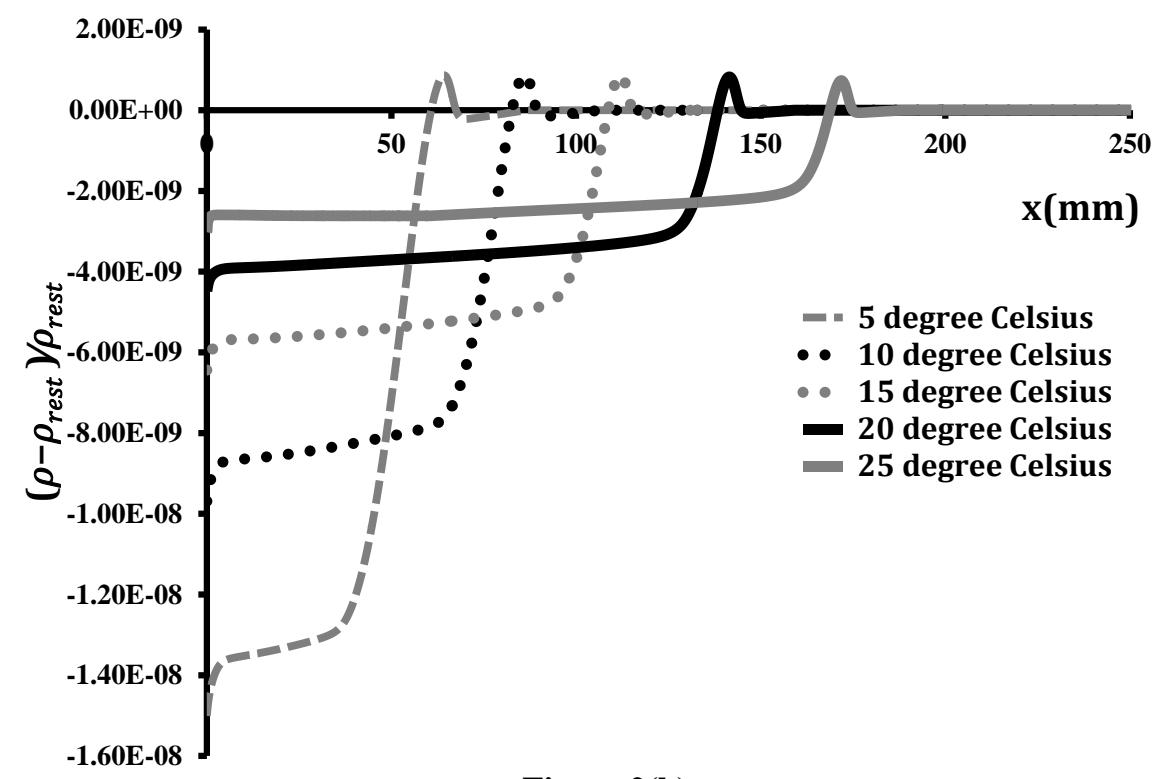

Figure 2(b)

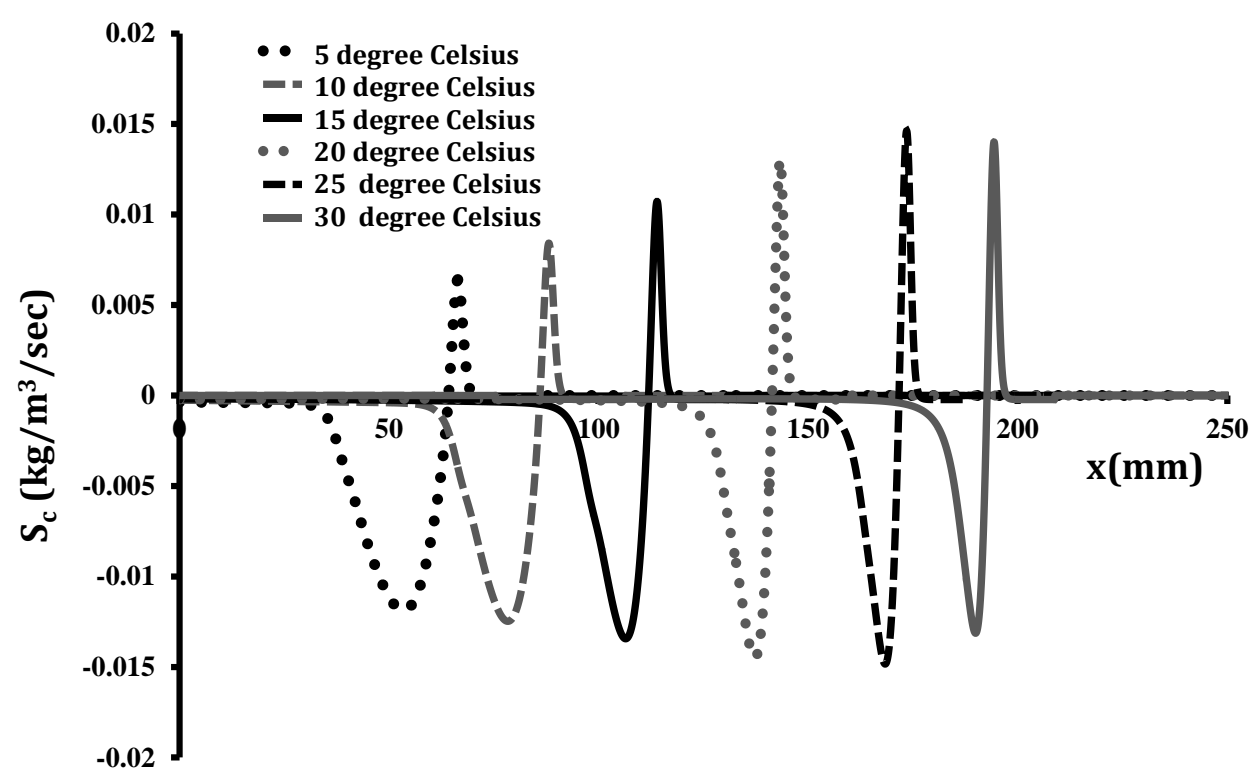

Figure 2(c) 


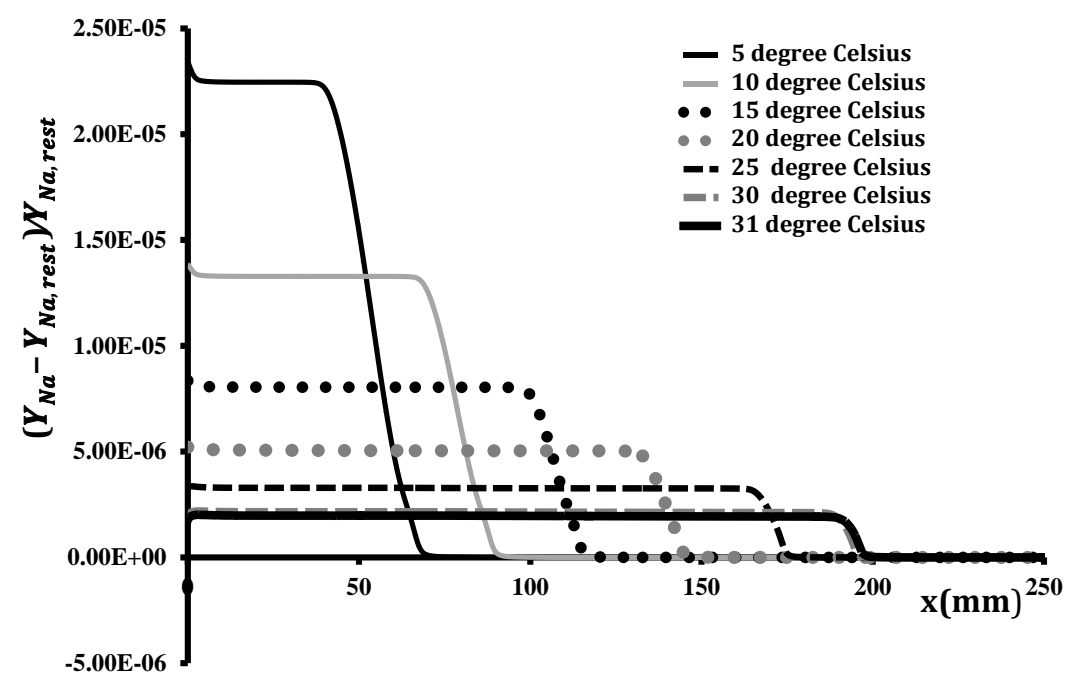

Figure 2(d)

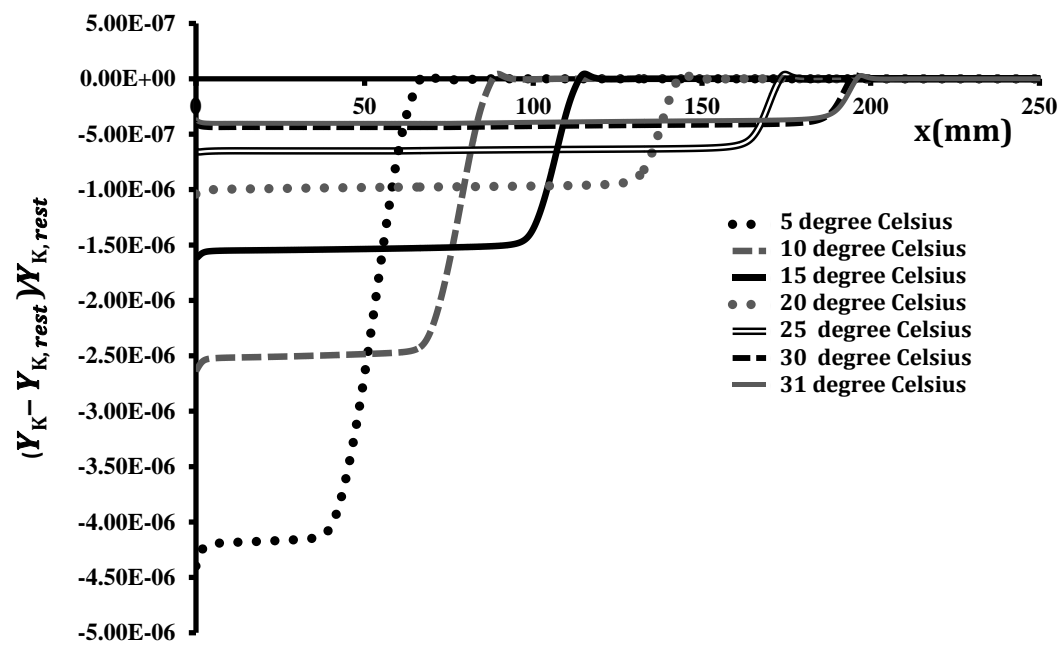

Figure 2(e)

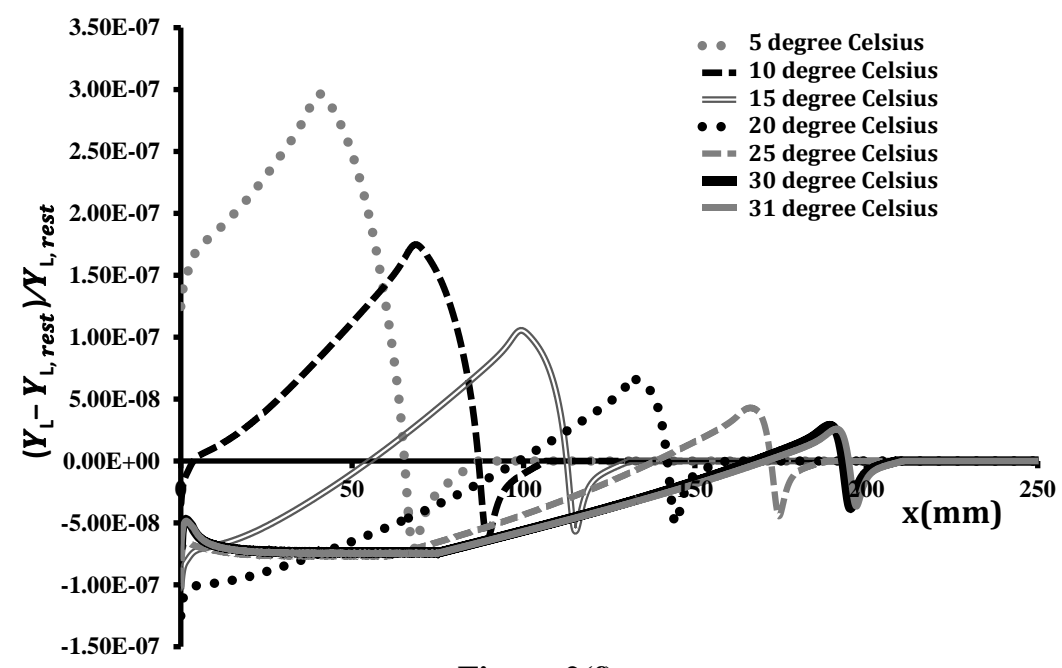

Figure 2(f)

Figure 2. Dependency of (a) membrane voltage, $V(m V)$ (y-axis), (b) normalized density, $\left(\rho-\rho_{\text {rest }}\right) / \rho_{\text {rest }}(y$-axis) (c) total rate of addition of all the three ions, $S_{c}(\mathrm{~kg} / \mathrm{m} 3 / \mathrm{sec}$ ) (y-axis), (d) normalized mass fraction of sodium ions $\left(\mathrm{Y}_{\mathrm{Na}}-\mathrm{Y}_{\mathrm{Na}, \text { rest }}\right) / \mathrm{Y}_{\mathrm{Na}, \text { rest }}\left(\mathrm{y}\right.$-axis), (e) normalized mass fraction of potassium ions $\left(\mathrm{Y}_{\mathrm{K}}-\mathrm{Y}_{\mathrm{K}, \text { rest }}\right) / \mathrm{Y}_{\mathrm{K}, \text { rest }}(\mathrm{y}$-axis) and (f) normalized mass fraction of chlorine ions $\left(\mathrm{Y}_{\mathrm{L}}-\mathrm{Y}_{\mathrm{L}, \text { rest }}\right) / \mathrm{Y}_{\mathrm{L}, \text { rest }}(\mathrm{y}$-axis) on temperature in the second temperature range has been plotted over the axonal length $\mathrm{x}(\mathrm{mm})$ (x-axis) 
Analyzing the Impact of Temperature from the Upper Boundary of the Temperature in Second Range Corresponding to the Different Parameters to 35 Degree Celsius

1. As can be seen from the graphs, that at a temperature of 34 degree Celsius and 35 degree Celsius, the values for all the parameters are almost overlapping and there is no conduction velocity/propagation velocity.

2. There is continuous declination in the peak of all parameters with further increase in temperature.

3. The membrane voltage reaches the resting potential of $-65 \mathrm{mV}$ at temperature of 34 degree Celsius and 35 degree Celsius.

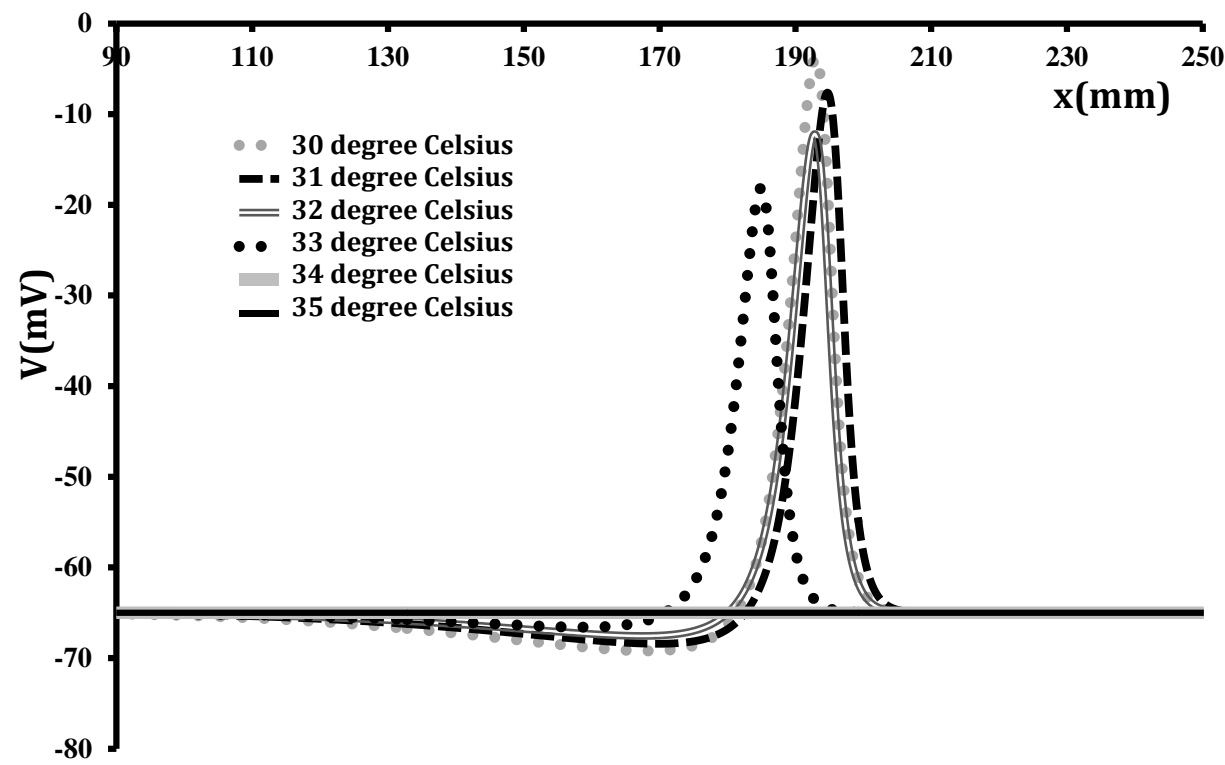

Figure 3(a)

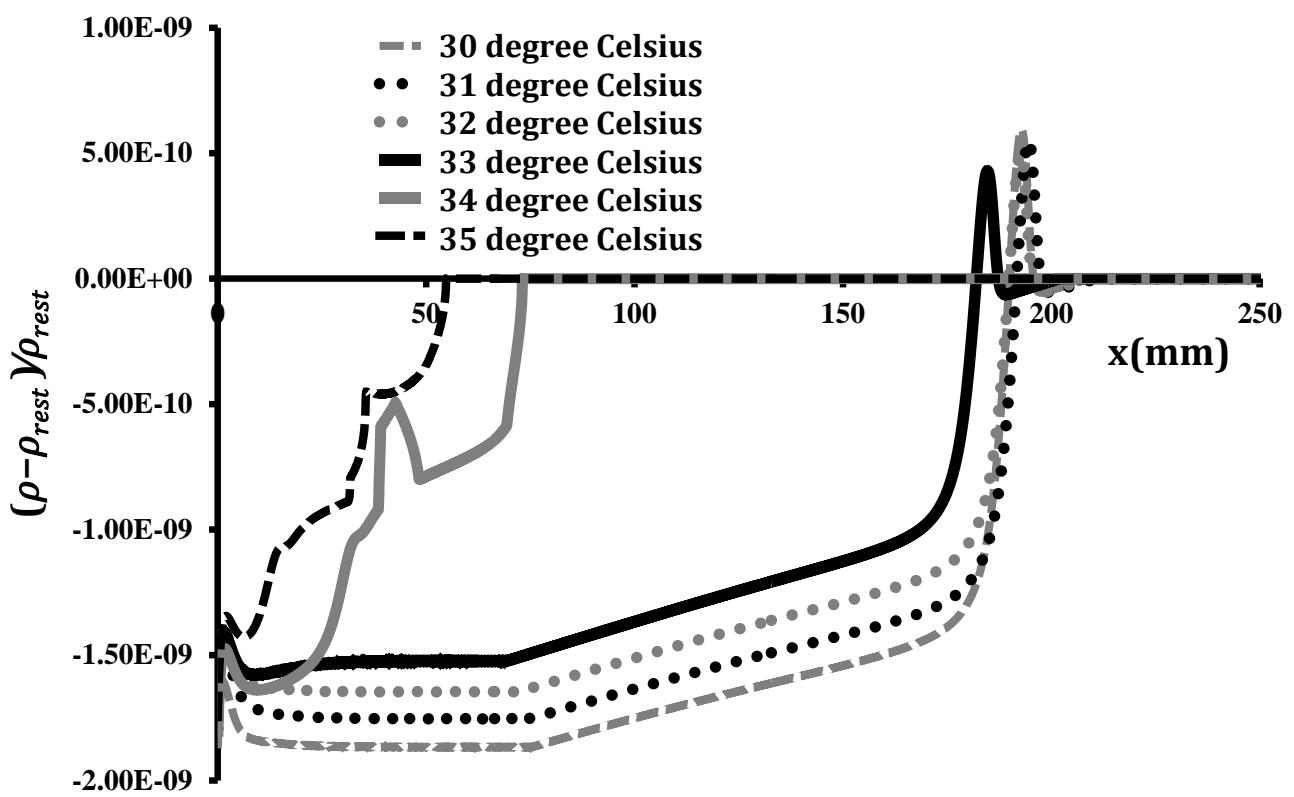

Figure 3(b) 


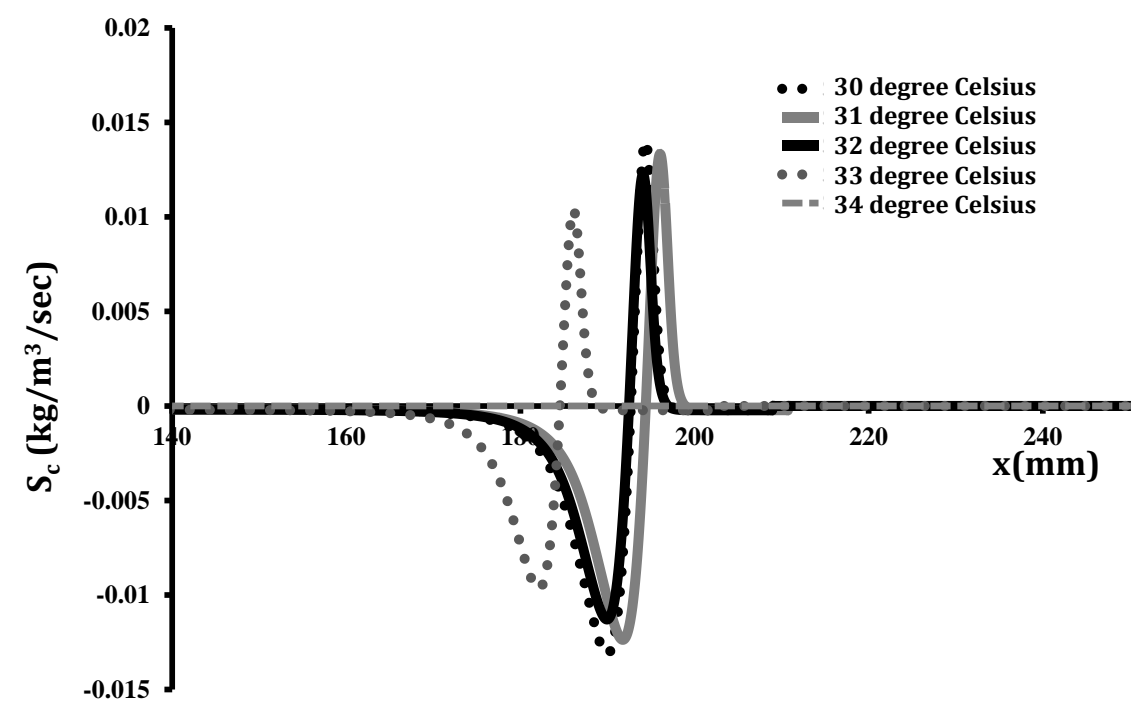

Figure 3(c)

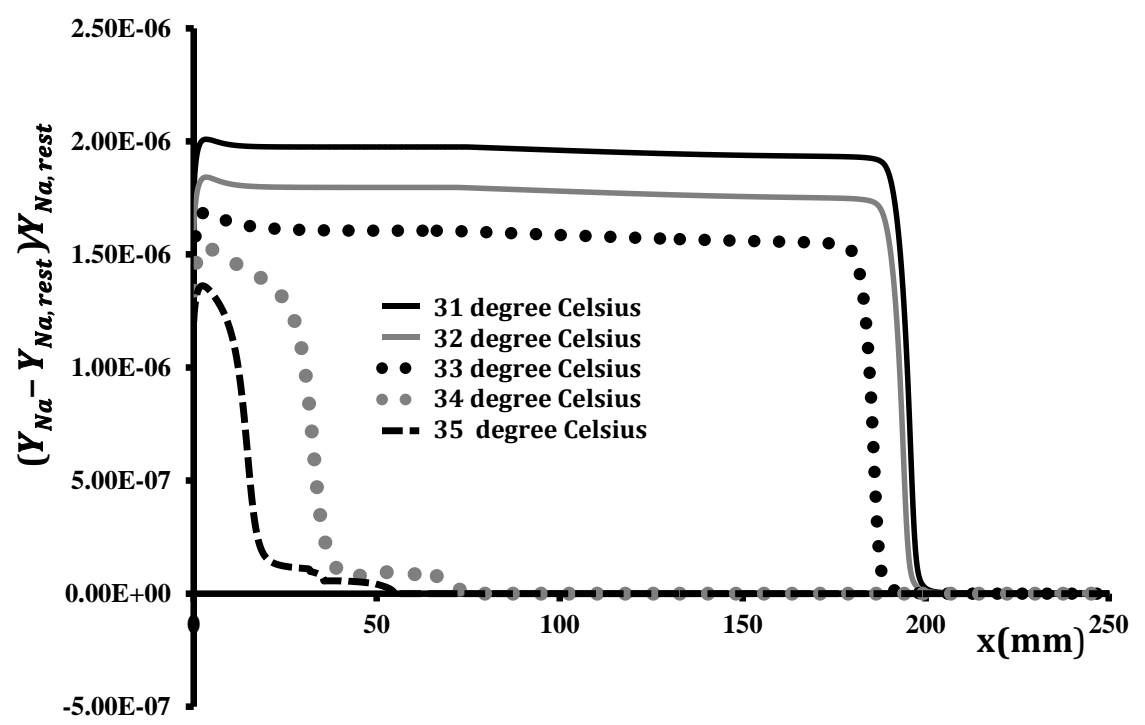

Figure 3(d)

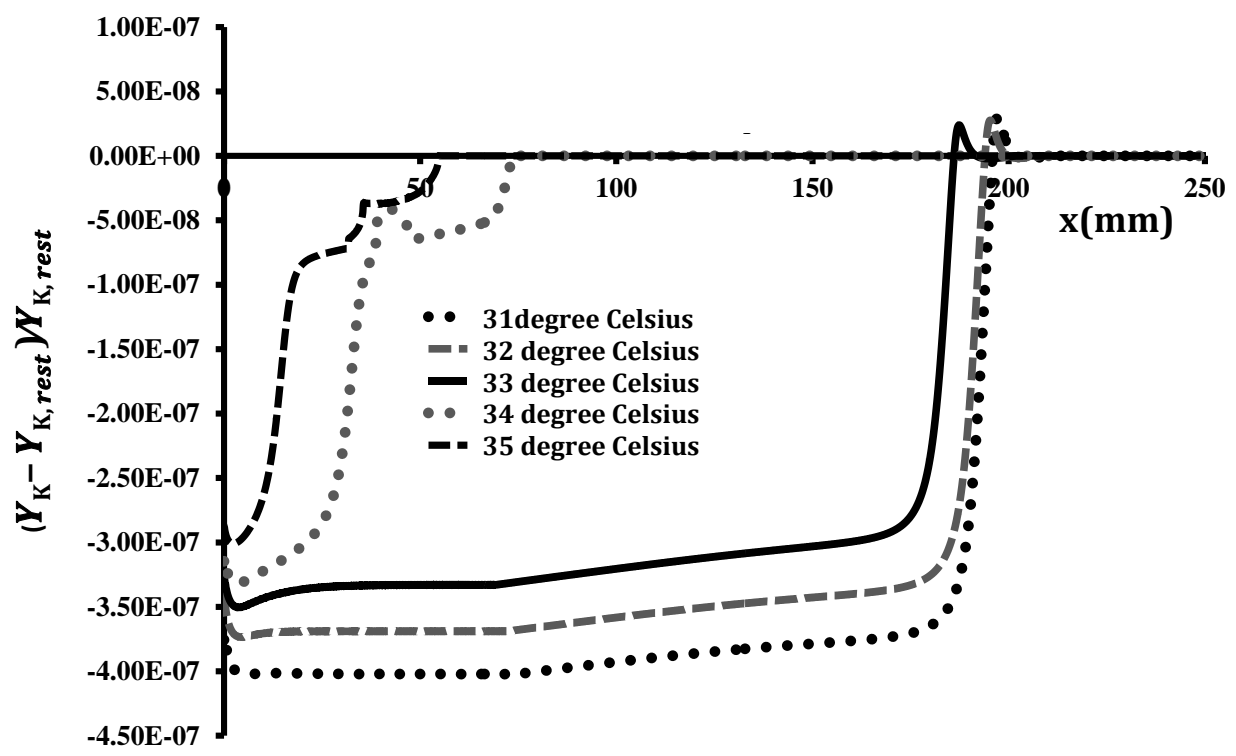

Figure 3(e) 


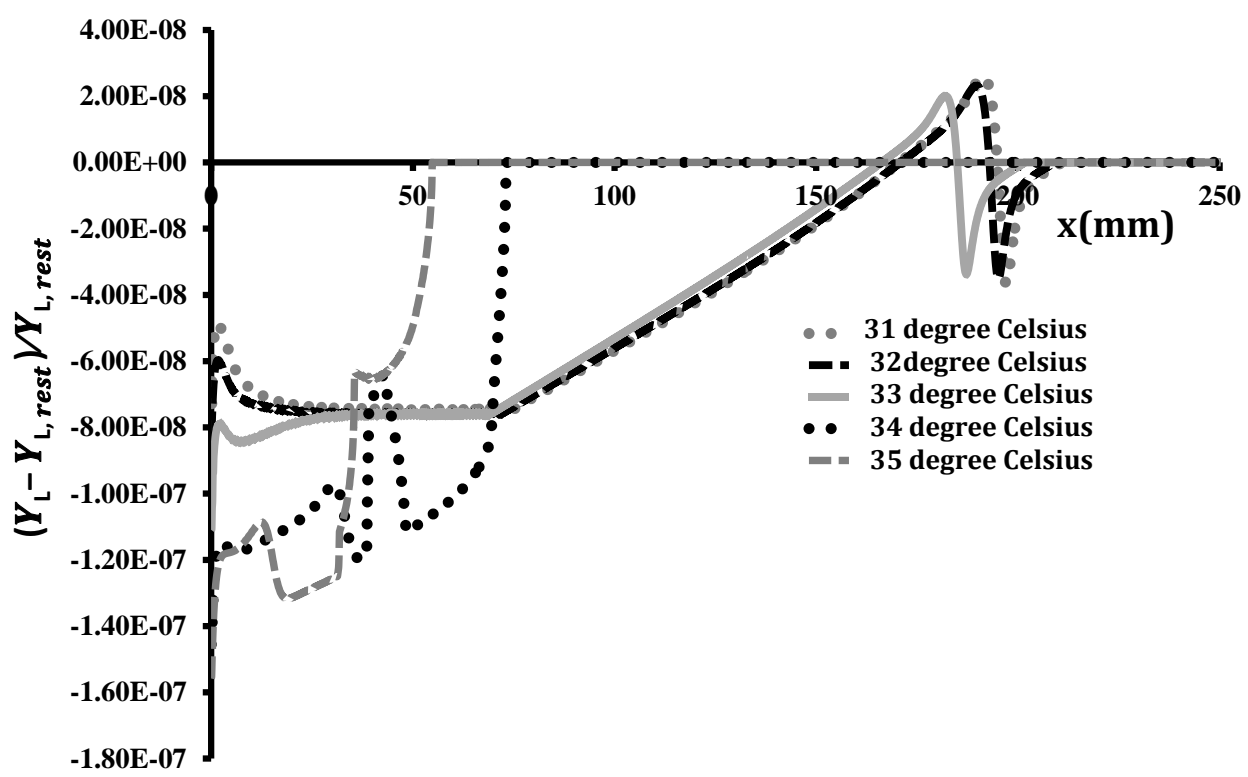

Figure 3(f)

Figure 3. Dependency of (a) membrane voltage, $V(m V)$ (y-axis), (b) normalized density, $\left(\rho-\rho_{\text {rest }}\right) / \rho_{\text {rest }}(y-a x i s)(c)$ total rate of addition of all the three ions, $S_{\mathrm{c}}(\mathrm{kg} / \mathrm{m} 3 / \mathrm{sec}$ ) (y-axis), (d) normalized mass fraction of sodium ions $\left(\mathrm{Y}_{\mathrm{Na}}-\mathrm{Y}_{\mathrm{Na}, \text { rest }}\right) / \mathrm{Y}_{\mathrm{Na} \text {,rest }}\left(\mathrm{y}\right.$-axis), (e) normalized mass fraction of potassium ions $\left(\mathrm{Y}_{\mathrm{K}}-\mathrm{Y}_{\mathrm{K}, \text { rest }}\right) / \mathrm{Y}_{\mathrm{K}, \text { rest }}(\mathrm{y}$-axis) and (f) normalized mass fraction of chlorine ions $\left(\mathrm{Y}_{\mathrm{L}}-\mathrm{Y}_{\mathrm{L}, \text { rest }}\right) / \mathrm{Y}_{\mathrm{L}, \text { rest }}(\mathrm{y}$-axis $)$ on temperature in the third temperature range has been plotted over the axonal length $\mathrm{x}(\mathrm{mm})$ ( $\mathrm{x}$-axis)

\section{CONCLUDING REMARKS}

Considering the importance of temperature as a thermodynamic variable and its role in biomedical applications [17], spike propagation and its frequency has been studied with respect to temperature in [18]. Wang et al. in [19] have highlighted the importance of regulating brain temperature since it is the brain temperature which plays a significant role in number of diseases like trauma, stroke, multiple sclerosis including mood disorders and also responsible for disorders resulting in neuron degeneration

In the present work, it is clear from the observations given under Results and Discussion section, that temperature impacts action potential and the other parameters defining axoplasmic fluid properties namely: density, mass fraction of ions and rate of addition of ions. It has been found that these parameters follow the same dependency on temperature as it is followed by an action potential. However the temperature coefficient defined by Q10of3 is valid only in the range of temperature from 5 degree Celsius to 25 degree Celsius and in the present work, impact of temperature has been identified in the range of -5 degree Celsius to 35 degree Celsius. So, this necessitates further investigating the following:

1. Identifying the temperature coefficient applicable for neuronal excitation that fits for a range of temperature wider than 5-25 degree Celsius.

2. Since hyperthermia and hypothermia have been identified for therapeutic intervention in seizures leading to brain disorders and cardiac attacks respectively, it carries significant importance to understand the behavior of different axoplasmic fluid parameters of a neuron with wide range of varying temperatures.

3. Cerebrospinal fluid in [20] has been examined for investigating the impact of Ebola virus, hence identifying more and more axoplasmic fluid parameters impacted by temperature can also give clearer picture of neuronal parameters responsible for Ebola virus.

4. The model can also be further investigated for reversing the effect of anesthesia, since the results given in [21] show that thermal conductivity of Nano fluids is enhanced with an increase in temperature. Hence this property can be utilized for reversing the anesthesia effect by increasing the thermal conductivity of axoplasmic fluid, thereby converting back the axoplasmic fluid in gel state that is more viscous to the fluid state (less viscous state). 


\section{NOMECLATURE}

$c_{m} \quad$ Membrane capacitance per unit area of membrane $\left[\mathrm{F} / \mathrm{m}^{2}\right]$

$D_{N a} \quad$ Diffusivity of sodium ions in the fluid $\left[\mathrm{m}^{2} / \mathrm{sec}\right]$

$D_{K} \quad$ Diffusivity of potassium ions in the fluid $\left[\mathrm{m}^{2} / \mathrm{sec}\right]$

$D_{L} \quad$ Diffusivity of chlorine ions in the fluid $\left[\mathrm{m}^{2} / \mathrm{sec}\right]$

$F \quad$ Faraday constant [C/mol]

$\bar{g}_{N a} \quad$ Conductance of sodium ions per unit area of membrane $\left[\mathrm{S} / \mathrm{m}^{2}\right]$

$\bar{g}_{K} \quad$ Conductance of potassium ions per unit area of membrane $\left[\mathrm{S} / \mathrm{m}^{2}\right]$

$\bar{g}_{L} \quad$ Conductance of chlorine ions per unit area of membrane $\left[\mathrm{S} / \mathrm{m}^{2}\right]$

$h \quad$ Inactivation variable for potassium ions [dimensionless]

$i_{a p p} \quad$ Current applied per unit area $\left[\mathrm{A} / \mathrm{m}^{2}\right]$

$K \quad$ Constant multiplied with water viscosity to obtain axoplasmic fluid viscosity [dimensionless]

$k_{B} \quad$ Boltzman Constant $[\mathrm{J} / \mathrm{K}]$

$m \quad$ Activation variable for sodium ions [dimensionless]

$M_{N a} \quad$ Molar mass of sodium ions $[\mathrm{kg} / \mathrm{mol}]$

$M_{K} \quad$ Molar mass of sodium ions $[\mathrm{kg} / \mathrm{mol}]$

$M_{L} \quad$ Molar mass of sodium ions $[\mathrm{kg} / \mathrm{mol}]$

$n \quad$ Inactivation variable for sodium ions [dimensionless]

$r \quad$ Axon radius [m]

$r_{i} \quad$ Radius of different ions $i[\mathrm{~m}]$

$R_{a} \quad$ Resistance per unit axial length $[\Omega / \mathrm{m}]$

$R_{u} \quad$ Universal gas constant \& $[\mathrm{J} / \mathrm{K} / \mathrm{mol}]$

$S_{c} \quad$ Total addition rate of ions per unit volume per unit time $\left[\mathrm{kg} / \mathrm{m}^{3} / \mathrm{sec}\right]$

$T \quad$ Temperature [K]

$V \quad$ Membrane voltage [V]

$V_{N a} \quad$ Equilibrium potential of sodium ions [V]

$V_{K} \quad$ Equilibrium potential of potassium ions [V]

$V_{L} \quad$ Equilibrium potential of chlorine ions [V]

$Y_{\mathrm{Na}} \quad$ Mass fraction of sodium ions [dimensionless]

$Y_{K} \quad$ Mass fraction of potassium ions [dimensionless]

$Y_{L} \quad$ Mass fraction of chlorine ions [dimensionless]

vis $\quad$ Axoplasmic fluid viscosity: Viscosity of fluid inside the axon [Pa.sec]

vis $\quad$ Viscosity of water [Pa.sec]

$z_{\mathrm{Na}} \quad$ Valency of sodium ions [dimensionless]

$z_{K} \quad$ Valency of potassium ions [dimensionless]

$z_{L} \quad$ Valency of chlorine ions [dimensionless]

$\dot{\omega}_{N a}^{\prime \prime \prime} \quad$ Rate of addition of mass of $\mathrm{Na}^{+}$ions through production or other means per unit volume $\left[\mathrm{kg} / \mathrm{m}^{3} / \mathrm{sec}\right]$

$\dot{\omega}_{K}^{\prime \prime \prime} \quad$ Rate of addition of mass of $\mathrm{K}^{+}$ions through production or other means per unit volume $\left[\mathrm{kg} / \mathrm{m}^{3} / \mathrm{sec}\right]$

$\dot{\omega}_{L}^{\prime \prime \prime} \quad$ Rate of addition of mass of $\mathrm{Cl}^{-}$ions through production or other means per unit volume $\left[\mathrm{kg} / \mathrm{m}^{3} / \mathrm{sec}\right]$

$\rho \quad$ Density (mass per unit volume) $\left[\mathrm{kg} / \mathrm{m}^{3}\right]$

\section{REFERENCES}

[1] Lodish H, Berk A, Zipursky SL, Matsudaira P, Baltimore D, Darnell J. Overview of Neuron Structure and Function. Molecular Cell Biology 4th edition. 2000.

[2] Bhatia S, Singh P, Sharma P. Hodgkin-Huxley model based on ionic transport in axoplasmic fluid. J Integr Neurosci. 2017;16(4):401-17. https://doi.org/10.3233/JIN-170029.

[3] Cook ND. The neuron-level phenomena underlying cognition and consciousness: synaptic activity and the action potential. Neuroscience. 2008 May 15; 153(3):556-70. https://doi.org/ 10.1016/j.neuroscience.2008.02.042.

[4] Yu Y, Hill AP, McCormick DA. Warm Body Temperature Facilitates Energy Efficient Cortical Action Potentials. PLOS Computational Biology. 2012 Apr 12; 8(4):e1002456. https://doi.org/ 10.1371/journal.pcbi.1002456.

[5] Hodgkin AL, Huxley AF. A quantitative description of membrane current and its application to conduction and excitation in nerve. J Physiol. 1952 Aug 28;117(4):500-44.

[6] Guttman R. Temperature Dependence of Accommodation and Excitation in Space-Clamped Axons. J Gen Physiol. 1968 Jun 1; 51(6):759-69. 
[7] Fitzhugh R. Theoretical Effect of Temperature on Threshold in the Hodgkin-Huxley Nerve Model. J Gen Physiol. 1966 May 1;49(5):989-1005. https://doi.org/ 10.1085/jgp.49.5.989.

[8] Chapman RA. Dependence on temperature of the conduction velocity of the action potential of the squid giant axon. Nature. 1967 Mar 18;213(5081):1143-4. https://doi.org/ 10.1038/2131143a0.

[9] Lv Y, Liu J. Interpretation on thermal comfort mechanisms of human bodies by combining HodgkinHuxley neuron model and Pennes bioheat equation. Forsch Ingenieurwes. 2005 Mar 1;69(2):101-14. https://doi.org/ 10.1007/s10010-004-0145-8.

[10] Nielsen N, Wetterslev J, Cronberg T, Erlinge D, Gasche Y, Hassager C, et al. Targeted temperature management at $33^{\circ} \mathrm{C}$ versus $36^{\circ} \mathrm{C}$ after cardiac arrest. N Engl J Med. 2013 Dec 5;369(23):2197-206. https://doi.org/ 10.1056/NEJMoa1310519.

[11] Peters C, Rosch RE, Hughes E, Ruben PC. Temperature-dependent changes in neuronal dynamics in a patient with an SCN1A mutation and hyperthermia induced seizures. Sci Rep. 2016 01;6:31879. https://doi.org/10.1038/srep31879.

[12] Walter EJ, Carraretto M. The neurological and cognitive consequences of hyperthermia. Crit Care. 2016;20. https://doi.org/ 10.1186/s13054-016-1376-4.

[13] Forrest MD. Can the Thermodynamic Hodgkin-Huxley Model of Voltage-Dependent Conductance Extrapolate for Temperature? Computation. 2014 Jun;2(2):47-60. https://doi.org/ 10.3390/computation2020047.

[14] Bhatia, S., Singh, P., Sharma, P. Hodgkin-Huxley Model Revisited to Incorporate the Physical Parameters Affected by Anesthesia. In: Pant M, Ray K, Sharma TK, Rawat S, Bandyopadhyay A, editors. Soft Computing: Theories and Applications: Proceedings of SoCTA 2016, Volume 1. Springer Singapore; 2018. (Advances in Intelligent Systems and Computing).

[15] Dayan, P., Abbott, L. F. Theoretical Neuroscience. The MIT Press.

[16] Gerstner, W., Werner M. Kistler. Spiking Neuron Models: Single Neurons, Populations, Plasticity. 1 edition. Cambridge University Press. 2002. https://doi.org/ 10.1017/CBO9780511815706.

[17] Daghighi Y. Microfluidic technology and its biomedical applications. Journal of Thermal Engineering. 2015;1(7):621-6.

[18] Fillafer C, Schneider MF. Temperature and excitable cells. Commun Integr Biol. 2013 Nov 1; 6(6). https://doi.org/10.4161/cib.26730.

[19] Wang H, Wang B, Normoyle KP, Jackson K, Spitler K, Sharrock MF, et al. Brain temperature and its fundamental properties: a review for clinical neuroscientists. Front Neurosci. 2014;8:307. https://doi.org/ 10.3389/fnins.2014.00307.

[20] Billioux BJ, Nath A, Stavale EJ, Dorbor J, Fallah MP, Sneller MC, et al. Cerebrospinal Fluid Examination in Survivors of Ebola Virus Disease. JAMA Neurol. 2017 01; 74(9):1141-3. https://doi.org/ 10.1001/jamaneurol.2017.1460.

[21] Estellé P, Halelfadl S, Maré T. Thermal conductivity of cnt water based nanofluids: experimental trends and models overview. Journal of Thermal Engineering. 2015 Apr; 1 (2):381-90. 